\title{
El fenómeno usuarios de la información desde un enfoque cognitivo
}

\author{
Patricia Hernández Salazar *
}

Artículo recibido:

10 de abril de 2013.

Artículo aceptado:

11 de mayo de 2013.

\section{Resumen}

El fenómeno usuarios de la información ha sido estudiado desde una perspectiva práctica. Básicamente se ha considerado como un asunto colateral al paradigma de la organización y no como lo que realmente es, un fenómeno interdisciplinario que puede estar basado en un enfoque cognitivo. El objetivo del presente documento es establecer como tendencia teórica tal enfoque para explicar todo lo concerniente al fenómeno usuarios de la información, aludiendo al proceso de pensamiento de un sujeto/usuario. Para cubrir este objetivo se tratan tres temas principales: las ciencias cognitivas, dando especial énfasis a la psicología cognitiva; el proceso de pensamiento denominado categorización, el

* Instituto de Investigaciones Bibliotecológicas y de la Información de la UNAM, México.phs75599@unam.mx

INVESTIGACIÓN BIBLIOTECOLÓGICA, Vol. 27, Núm.61, septiembre/diciembre, 2013, México, ISSN: 0187-358X. pp. 107-131 
cual permite generar las necesidades y los comportamientos de los sujetos ante la información; y los autores que han seguido el enfoque cognitivo para estudiar el tema usuarios. Finalmente se incluyen algunas conclusiones que pueden guiar futuros trabajos sobre el tema.

Palabras clave: Usuarios de la información; Enfoque cognitivo.

\section{Abstract}

A cognitive approach to the information user phenomenon

Patricia Hernández-Salazar

The information user as a phenomenon has been studied from a practical standpoint, frequently considered a collateral issue in the organization paradigm; though it is in fact an interdisciplinary phenomenon, which can be examined using a cognitive approach. The objective of this paper is to advance the cognitive approach, entailing users' thought processes, as a theoretical basis for explaining the phenomenon of information users. To this end, three main topic areas are discussed: 1) cognitive sciences, with special regard to cognitive psychology, which is the basis of this approach; 2 ) the thought process procedure we call categorization, which underpins a subject's information needs and behaviors, and 3) the body of cognitive approach research focusing on users. Avenues for further research are offered in the conclusions.

Keywords: Information users; Cognitive approach.

\section{INTRODUCCIÓN}

T a construcción de cualquier disciplina requiere generar marcos teóricos Lque expliquen cada uno de sus campos y subcampos fenoménicos, explicaciones que permitan desvelar con claridad y detalle aquello que estaba oscuro y confuso; una explicación intenta responder a la pregunta por qué algo es como es o sucede como sucede. 
Explicar alude a un compromiso de acomodar las ideas y exponerlas de tal manera que sean inteligibles y consistentes; una idea antecede a otra y de ésta deriva otra, siempre con un entramado relacional lógicamente desarrollado. Para que podamos vincular las ideas y resultados que se producen en el estudio de un fenómeno es menester atender a una tendencia teórica que sirva de base para tejer cada hebra de pensamiento. En este caso atenderemos al enfoque cognitivo para explicar nuestro campo de investigación, el usuario. Cabe aclarar que se concibe al usuario como sujeto y objeto/fenómeno de investigación, es decir, el referente no debe ser sólo un sujeto sino el conglomerado de términos, frases, ideas y subcampos de estudio que lo conforman.

El tema de los usuarios ha sido abordado desde diversas tendencias paradigmáticas, positivismo, ${ }^{1}$ empirismo ${ }^{2}$ y pragmatismo ${ }^{3}$ entre otras, y todas ellas lo ubican como dependiente o subordinado a la organización (de colecciones) a la cual debe adaptarse. Esto se debe básicamente al paradigma que ha imperado en la disciplina bibliotecológica y de información, la organización como su objeto de estudio. Afortunadamente este paradigma está cambiando del interés por la organización hacia la información y sobre todo hacia aquel que la usa, afianzándose la idea paradigmática del uso/usuario como base epistemológica.

Durante varias décadas la disciplina tuvo su sustento en la investigación sobre la recuperación de información y no en el sujeto que recupera esa información. Todavía en la década de 1990, Ellis (1992) hace un análisis y descripción de los paradigmas de la disciplina, poniendo especial énfasis en la recuperación y no en el usuario, e incluso algunos autores no manejaban el término como tal, sino el de receptor, ya que consideraban a un sujeto como si éste estuviera dentro del sistema de comunicación.

Ellis analiza la tendencia paradigmática cognitiva a partir de la recuperación de información, atendiendo al concepto de paradigma de Kuhn (2001) y entendiéndolo como el elemento central compartido por un grupo de sujetos, como el componente esencial en el que se basan los compromisos compartidos de este grupo. Considera que los elementos que conforman una matriz disciplinaria son cuatro: generalizaciones simbólicas, creencias metafísicas, valores y ejemplares. Un paradigma debe permear estos elementos en las concepciones de los sujetos que generan y sustentan una ciencia o disciplina.

1 Doctrina que considera importante la experiencia, los hechos, lo cierto, efectivo y verdadero, a lo que llama positivo.

2 Es una tendencia filosófica de carácter epistemológico que postula que la generación de conocimiento deriva de la experiencia de los sentidos, donde tanto el origen como la validez del conocimiento deben ser confirmados por los sentidos.

3 Teoría que permite otorgarle significación a las proposiciones, esta significación consiste en las consecuencias futuras de experiencias que ocurrirán, sin importar que esto se crea o no. 
También retoma la idea de Kuhn sobre los dos tipos del estado de las ciencias, preparadigmático y paradigmático. La ciencia paradigmática está guiada por un solo paradigma y en caso de que esto no suceda en una comunidad epistémica, entonces la ciencia es preparadigmática; la madurez de una ciencia dependerá de establecer puntualmente su naturaleza. De acuerdo con esta idea las disciplinas bibliotecológica y de la información están en un estado preparadigmático,

Este autor delimita dos paradigmas que han regido el fenómeno recuperación de información: el físico y el cognitivo.

En el paradigma físico el sistema de recuperación es visto como una herramienta física, por su naturaleza y por el tipo de técnicas que se emplean para evaluarlo, las cuales son de tipo experimental; se crean laboratorios o ambientes artificiales dentro de los cuales la actuación del sistema es probada (testing-test) entre grupos de personas; este paradigma también se conoce como el paradigma de pruebas porque mide el funcionamiento de un sistema sin considerar los requerimientos del sujeto, sino los de los bibliotecarios.

Por su parte, el paradigma cognitivo se basa en el mundo cognitivo del usuario, que considera a éste como elemento básico para el diseño de un sistema de recuperación de información, aquí ya es importante la interacción entre el usuario y el sistema.

El presente artículo persigue establecer como tendencia teórica el enfoque cognitivo para explicar todo lo concerniente al fenómeno usuarios de la información aludiendo al proceso de pensamiento de un sujeto/usuario. Para cubrir este objetivo se tratan tres temas principales, en el primer apartado se definen las ciencias cognitivas, dándole especial énfasis a la psicología cognitiva pues es la base del entendimiento de los procesos mentales de los sujetos.

El siguiente apartado describe ampliamente el proceso de pensamiento denominado categorización, el cual permite generar las necesidades y los comportamientos de los sujetos ante la información. La tercera sección presenta a los autores que han seguido el enfoque cognitivo para estudiar campos fenoménicos como la recuperación de información y justamente a los sujetos que la recuperan, es decir, los usuarios.

Finalmente se incluyen algunas conclusiones que pueden guiar futuros trabajos sobre el tema.

\section{Ciencias cognitivas}

De acuerdo con el paradigma cognitivo el usuario se convierte en el eje alrededor del cual giran las parcelas del conocimiento bibliotecológico. Si el usuario 
es un sujeto, debe ser concebido como un ente que conoce y no sólo como un objeto o elemento del ciclo de producción y transferencia de información. El usuario es un sujeto que piensa, que realiza procesos mentales para ser y para existir, de aquí que se retomen las ciencias cognitivas para abordarlo.

Las ciencias cognitivas son una aproximación inter y transdisciplinaria, que empieza a desarrollarse en 1950, y se entiende como un conjunto de ideas único y organizado que nos enseña a pensar sobre la mente y los procesos mentales, ideas que provienen de varias disciplinas que aquí convergen o se intersectan con todas las disciplinas que trabajan problemas específicos relacionados con la mente (mundo mental o espacio interno) y que abarcan procesos mentales tales como percepción, atención, imaginación, categorización, memoria, lenguaje y solución de problemas (Friedenberg y Silverman, 2006).

Lo anterior se basa en tres principios: computación, representaciones y perspectiva interdisciplinaria, tal como se muestra en la Figura 1:

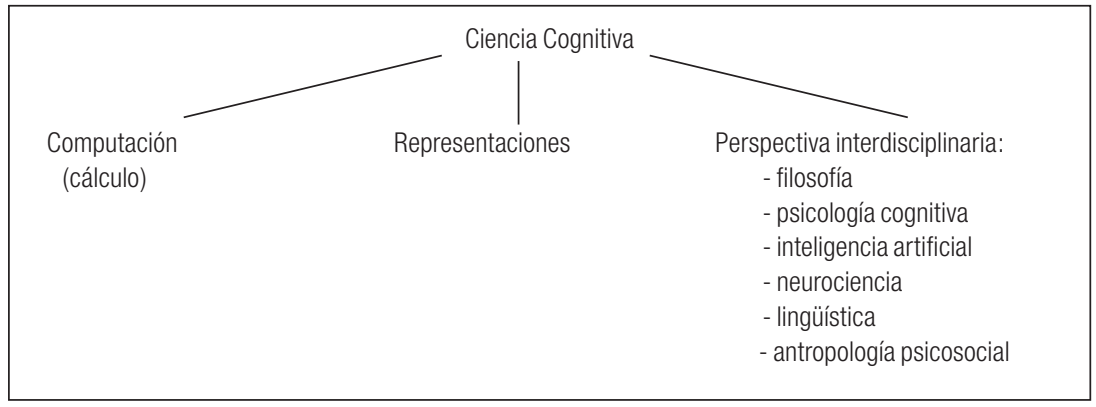

Figura 1. Principios de las ciencias cognitivas

\section{Computación}

La perspectiva teórica en la que subyacen las ciencias cognitivas es la idea de computación (medición o expresión de magnitudes), y la programación y la solución de problemas por el ser humano se ubican como sistemas de procesamiento de la información; al ser ambos mecanismos que tratan y expresan símbolos el modelo se puede describir de la siguiente manera: la mente es vista como una máquina o mecanismo que adquiere, representa, retiene, transforma y declara información.

La información es la energía de entrada (input) del proceso, ésta es percibida por la mente a través de los sentidos (ver, oír), se almacena en la memoria y/o se procesa (pensar/generar pensamientos), lo que origina una expresión de lenguaje o un comportamiento físico (outputs). La representación gráfica de este proceso se muestra en la Figura 2: 


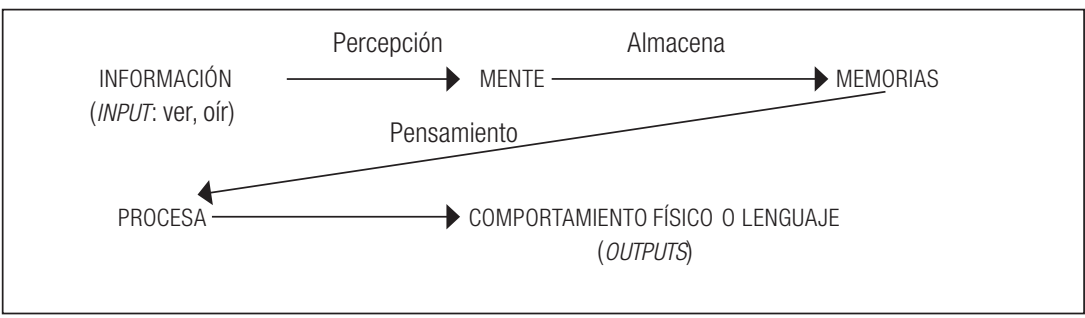

Figura 2. Computación o proceso de la información

La mente realiza cálculos sobre las representaciones, los cuales están dados por las operaciones mentales entre las que se pueden incluir: sensación, percepción, atención, memoria, lenguaje, razonamiento matemático, razonamiento lógico, tomar decisiones y solucionar problemas (Friedenberg y Silverman, 2006).

\section{Representaciones}

El cálculo (cómputo) en la mente está dirigido a las representaciones, éstas son entendidas como aprehensiones intencionales de un objeto, son las entidades simbólicas que un sujeto posee y/o genera y acomoda, están organizadas en estructuras conceptuales, procedimentales y actitudinales que permiten darle sentido a la interioridad y exterioridad de su entorno: representaciones internas de la realidad o del mundo externo.

La apropiación de objetos o representaciones es intencional y está relacionada con el referente, los objetos que están en el mundo son aprehendidos de acuerdo con los intereses y referentes del sujeto, estas representaciones mentales serán eventualmente expresadas y se convertirán en lingüísticas (semánticas) con un significado que será interpretable por alguien; de un estadio de representación individual se pasa a uno social.

De acuerdo con Friedenberg y Silverman la intencionalidad tiene dos propiedades:

[...] isomorfismo, o similitud de estructura entre una representación y su referente [...] Una segunda característica de la intencionalidad tiene que ver con la relación entre entradas y salidas del mundo [...] la activación de una representación (por ejemplo, pensar acerca de algo) debería generar comportamientos o acciones que de alguna manera están relacionadas con el referente (2006: 5-6).

Retomando estas propiedades la imagen de la construcción de representaciones se puede ver en la Figura 3: 


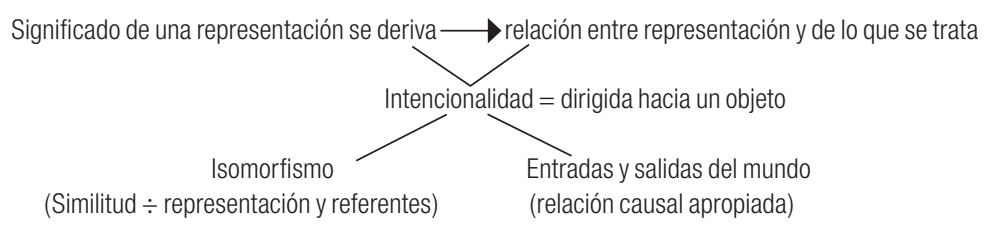

Figura 3. Construcción de representaciones

La mente construye representaciones de una realidad actual, reproducciones en la conciencia de percepciones pasadas y de anticipaciones de eventos futuros, todas al mismo tiempo, de aquí que la característica esencial de una representación es rebasar lo inmediato aumentando sus dimensiones en el espacio y en el tiempo.

Si bien las representaciones al ser intencionales son producto de la actividad mental de un sujeto, éste forma parte de un grupo social que introduce elementos supraindividuales o sociales: contexto en el que se sitúan los sujetos, comunicación que establecen y marcos culturales de aprehensión (códigos, valores e ideologías); es decir, representaciones sociales.

Existen cuatro categorías básicas de representaciones: concepto, proposiciones, reglas y analogías, cada una de ellas corresponde a un estadio de procesamiento de la información y generación de conocimiento:

- Concepto. Esencia, lo que es, forma y caracteres comunes a una cosa o grupo de cosas. Entidad individual o grupo de entidades, atributo de carácter abstracto.

- Proposiciones. Los conceptos se relacionan y se crean aseveraciones acerca del mundo, estas proposiciones lingüísticamente están conformadas por oraciones.

- Reglas. Se encargan de establecer las relaciones entre proposiciones.

- Analogías. Permiten comparar dos situaciones similares (Friedenberg y Silverman, 2006).

Como se puede apreciar el proceso de pensamiento es secuencial, primero producimos representaciones conceptuales, luego las proposicionales y después las reglas, una vez que esto se ha realizado relacionamos analógicamente la nueva información para procesarla y acomodarla en nuestro acervo de conocimientos.

Concretamente, la ciencia cognitiva estudia el contenido, la estructura, la función y el desarrollo de las representaciones mentales explicadas. 


\section{Perspectiva interdisciplinaria}

La conceptuación de las ciencias cognitivas lleva explícitamente la cualidad interdisciplinaria, el conocimiento no está parcelado, la cooperación y comunicación entre disciplinas es su principio rector. Las ciencias cognitivas abarcan la filosofía de la mente, la inteligencia artificial, la neurociencia, la lingüística, la antropología psicosocial y la psicología cognitiva, entre otras.

De las disciplinas cognitivas mencionadas la que nos ocupará es la psicología cognitiva, ya que su objeto de estudio es la mente humana, los procesos mentales y más concretamente la representación y uso del conocimiento. Con esta sola aproximación conceptual queda manifiesta la relación entre esta disciplina y el usuario en el contexto bibliotecológico y de información, nos interesa establecer que el usuario es un sujeto que conoce, y a partir de la representación y uso del conocimiento, genera y usa información. Existe un vínculo muy estrecho entre psicología cognitiva - sujeto / usuario que conoce - generación y uso de información, lo cual se expresa gráficamente en la Figura 4.

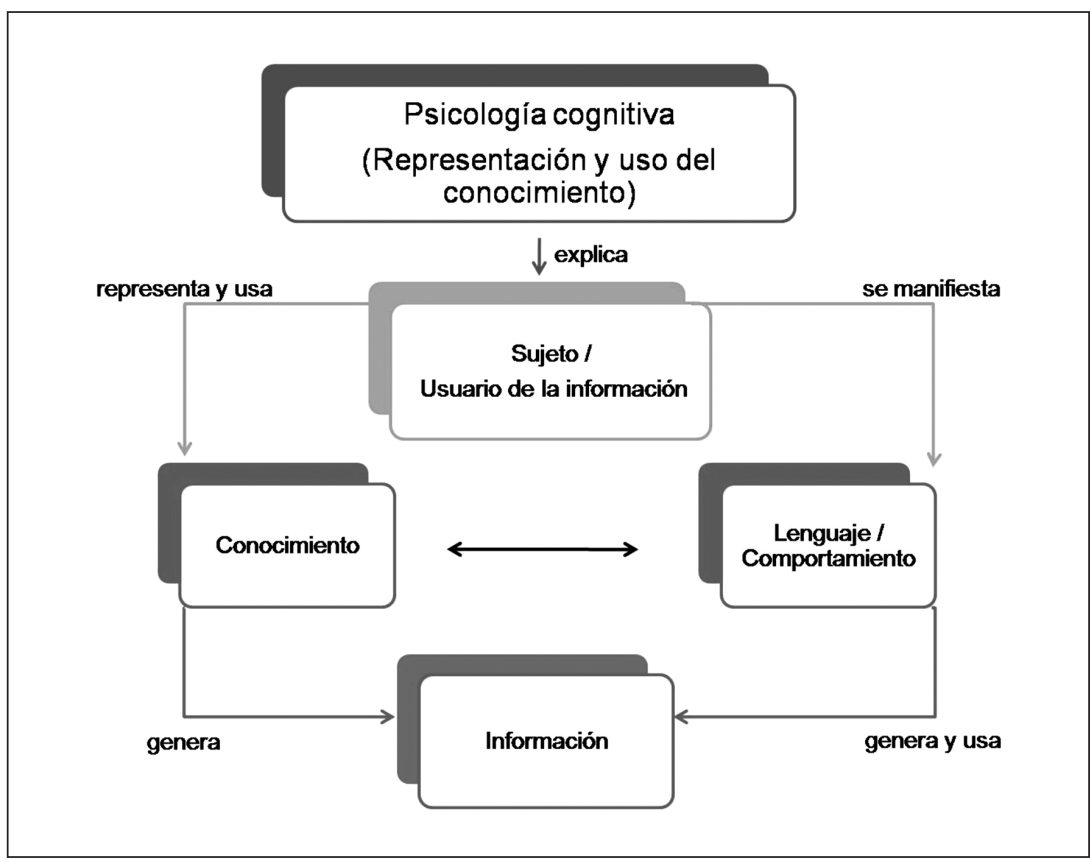

Figura 4. Relación entre psicología cognitiva y el fenómeno usuarios

Desde esta perspectiva podremos explicar quién es el usuario y cómo se vincula con la información, desde él mismo y no de lo que debe ser. 
El interés por los procesos mentales superiores empieza a desarrollarse en los años anteriores a la Primera Guerra Mundial, pero se dirigió hacia la conducta y la personalidad sin profundizar en el estudio puntual de la mente. De acuerdo con Bruner, Goodnow y Austin (1967) las principales causas que dieron origen a la psicología cognitiva fueron:

1. Crítica al conductismo. Las teorías estímulo-respuesta no consideraban los eventos que podían ocurrir entre la entrada de un estímulo físico y la emisión de una respuesta observable. Dejaban de lado los procesos complejos que median entre el estímulo clásico y las respuestas. La psicología cognitiva empezó a delinear los mapas cognitivos de los sujetos, es decir, el camino que recorre un estímulo y cómo se acomoda antes que ocurra cualquier respuesta.

2. Teoría de la información. Es una de las teorías que sigue el principio cognitivo de la mente como un mecanismo de cómputo. Reconocieron que las entradas y salidas de esta máquina eran aparentes, y que no se podía explicar el proceso sólo considerando la naturaleza de esos momentos, se requería tomar en cuenta las características internas como capacidad del canal y ruido. La codificación y recodificación de entradas, es decir, cómo son sorteadas y organizadas las señales se convirtió en el secreto del canal de comunicación a descifrar. Influyeron teorías como la de Shannon; ${ }^{4}$ la de los autómatas representada por la Máquina de Turing ${ }^{5}$ y la de Cibernética de Norber Wiener ${ }^{6}$ (Martorell y Prieto, 2002).

3. Desarrollo de nuevas máquinas de medición, las cuales fueron utilizadas para medir procesos mentales. Algunos ejemplos de máquinas son: Positron Emission Tomography (PET), Computerized Axial Tomography (CAT) y Magnetic Resonance Imaging (MRI).

La psicología cognitiva aparece entre 1950 y 1960; sin embargo, la frase es usada ampliamente a finales de los sesenta. Existen diversas acepciones de la misma, retomaremos aquí la definición que da Ulric Neisser (1967: 10) quien fue uno de los primeros en escribir sobre ella: "se refiere generalmente al

4 Estableció que la información que era transmitida por cualquier canal podía medirse matemáticamente. Su modelo consta de cinco elementos: fuente de información, transmisor, canal, receptor y destinatario.

5 Un autómata es cualquier mecanismo con movilidad o una máquina que ejecuta un programa de ordenador. La Máquina de Turing fue diseñada como un autómata de estados finitos, cuyo propósito era realizar cualquier tipo de cálculo.

6 Propone que los seres vivos y algunos sistemas de ingeniería tienen similitudes en cuanto a un comportamiento que él llamó propositivo, es decir, que siguen un propósito. 
estudio de los mecanismos cognitivos", y estos son "todos los procesos en los que la entrada sensorial es transformada, reducida, elaborada, almacenada, recobrada y usada" (1967: 4); concretamente se centra en el procesamiento humano de la información.

Algunas características de esta disciplina son:

- Utiliza un nuevo lenguaje para explicar los hallazgos: el del procesamiento de la información.

- Se basa en la conducta observable, aunque postula estructuras mentales internas.

- Lo que observa directamente son los productos externos de los procesos mentales y no a ellos mismos.

- Considera al sujeto como un ente activo respecto al medio en que vive, capaz de autorregularse y de generar planes de conducta para alcanzar las metas que persigue.

Cabe mencionar que el lenguaje es un factor determinante en el desarrollo de la psicología cognitiva, uno de los fracasos del conductismo fue la imposibilidad para explicar la adquisición del lenguaje, de aquí que haya una gran influencia de las teorías del lenguaje como la Gramática Transformacional de Chomsky. ${ }^{7}$

En lo anteriormente expuesto encontramos el elemento lenguaje, lo que viene a redondear la relación que se había establecido entre psicología cognitiva y usuario, pues el sujeto que piensa, genera y usa conocimiento también lo expresa mediante un lenguaje ya sea oral o escrito; así podremos abordarlo e interpretarlo. No utilizamos la palabra describirlo porque un sujeto no puede ser descrito cabalmente, los estados mentales de los otros se tienen que inferir, es decir, interpretarse.

Esta somera aproximación a los principios que rigen las ciencias cognitivas pone de manifiesto la relevancia que puede tener y tiene considerar la tendencia cognitiva como base para explicar el fenómeno usuarios, ya que éste es un sujeto que realiza procesos mentales: percibe, categoriza, adquiere, retiene, crea representaciones y transforma la información. Lo importante será entender cómo realiza estos procesos para poder comprenderlo y apoyarlo para que resuelva sus problemas y necesidades cognitivas y de información.

7 Para Chomsky el lenguaje es un sistema finito de reglas que genera las infinitas oraciones de la lengua, asimismo estableció que las frases constan de dos niveles estructurales: una estructura superficial, que es la de cada lengua, y una profunda, que corresponde a los universales lingüísticos y son de carácter humano. 


\section{Categorización, NeCEsidades y COMPORTAMientos} ANTE LA INFORMACIÓN

Ahora bien, de todos los procesos de cognición que realiza un sujeto mencionados en la explicación de ciencias cognitivas y psicología cognitiva, nos interesa específicamente la capacidad humana de categorizar, pues es una función principal de la conceptualización. De acuerdo con Bruner, Goodnow y Austin es la posibilidad de:

[...] convertir discriminatoriamente cosas que son diferentes en equivalentes, agrupar los objetos, eventos y a la gente que nos rodea en clases, y responderles en términos de su pertenencia a dicha clase más que a su carácter de única. Nuestra actividad de discriminación refinada está reservada sólo para aquellos segmentos del ambiente que especialmente nos importan. Para el resto, respondemos en formas más que crudas de acomodamiento categorial (1967: 1).

La construcción de categorías es un proceso de codificación y recodificación en el que los sujetos retrotraen sus historias pasadas y consideran los requerimientos presentes a los que se están enfrentando; es un acto que atiende al acervo de conocimientos y emociones o estados afectivos que un sujeto posee, de ahí que se deben identificar las precondiciones (situacional y de historia pasada) que lo llevan a agrupar los estímulos de una manera y no de otra, y las diferencias sistemáticas tanto individuales como culturales para categorizar un comportamiento (Bruner, Goodnow y Austin, 1967). La creación de categorías depende del mundo circundante del sujeto: cultura, estilo de vida, religión, ciencia, historia personal, tradiciones y lenguaje.

Existen dos niveles de categorización mediante los cuales acomodamos las cosas que nos llegan: perceptual y conceptual.

- Perceptual. Es un acto de identificación, a partir de los atributos que definen a un estímulo de entrada éste se acomoda en una cierta clase, generalmente es a nivel de los sentidos y corresponde a la primera etapa del modelo o principio teórico de la mente como un mecanismo de procesamiento de información.

- Conceptual. Además del nivel anterior involucra la concordancia de un conjunto de objetos o ejemplos en las especificaciones de una categoría.

Uno y otro se diferencian por la inmediatez para sentir y acomodar los atributos de los objetos dentro de una categoría, en la perceptual los atributos son 
dados inmediatamente y el proceso es más simple. Por su parte el conceptual requiere una estrategia de búsqueda y acomodo más compleja.

Los seres humanos experimentan ambos niveles de categorización cotidianamente, la diferencia estará en la intención de los sujetos para aprehender los objetos del mundo: percibirlos en forma inmediata o conceptuarlos y recuperarlos más tarde.

La motivación para categorizar es un estado de necesidad del organismo que se relaciona con la selectividad perceptual y conceptual, y asimismo la actividad cognitiva está asociada a estados afectivos únicos. El proceso de categorización es una tensión constante, tratar de acomodar a algo o alguien dentro de una clase y no lograrlo o lograrlo en parte nos hace sentir frustrados y volver a empezar o continuar el proceso; estamos ante una presencia de necesidad cognitiva generalizada.

Esta necesidad del organismo por categorizar, por identificar y acomodar estímulos para disminuir la tensión y la frustración de los sujetos explica las necesidades de información de los usuarios, así como la activación de ciertas acciones inconscientes que se reflejan en una forma lingüística (requerimientos) o en un comportamiento en la búsqueda, recuperación y uso de la información, para eventualmente cubrir esos requerimientos o necesidades.

El lenguaje resulta básico en todos los procesos mentales, pues las representaciones, categorizaciones y conceptuaciones se realizan con una imagen simbólica dada por los signos lingüísticos, letras, palabras, frases. Una vez que se ha aprendido un lenguaje es imposible recuperar o recordar un fluido indiferenciado de sonidos de voz; escuchamos antes de darle sentido a ese fluido mediante el lenguaje.

Lo anterior se puede representar de la siguiente manera: tenemos una cadena de conocimientos a la que en algún momento (ante un estímulo nuevo) se le rompe un eslabón, para repararlo tenemos necesidad de identificar los atributos o características del estímulo y acomodarlo en alguna clase, que corresponderá al eslabón reparado, aquí entra también el elemento afectivo, que actúa como la retroalimentación que regula el flujo del comportamiento para solucionar un problema o necesidad, lo que tiene que ver con:

- reducir la complejidad del ambiente,

- identificar los objetos del mundo que nos rodea,

- reducir la necesidad de un aprendizaje constante,

- dirigir la actividad instrumental y

- ordenar y relacionar clases de eventos (Bruner, Goodnow y Austin, 1967). 
Con lo anterior se refuerza la conveniencia de explicar el fenómeno usuarios desde un enfoque cognitivista, lo que interesa es llevar estas intenciones de categorizar al plano de la información: ¿cómo identifica el usuario los objetos del mundo informativo? ¿Cómo ordena y relaciona las clases de eventos que suceden en ese entorno? ¿Está reduciendo la necesidad de un aprendizaje constante?

Como podemos darnos cuenta, la categorización implica varios procesos mentales como percibir y atender, y ahora aparece el acto de solución de problemas aparejado con la toma de decisiones. Estos dos últimos están directamente relacionados con el tipo de categorización conceptual, es decir el proceso para lograr o generar conceptos.

En párrafos anteriores se expresó que el acto de categorizar y concretamente de lograr conceptos varía de un sujeto a otro; sin embargo, siempre implica que la serie de eventos que se suceden puede ser descrita como serie de decisiones que son contingentes; estas decisiones generan consecuencias, las cuales tendrán que ser evaluadas como razonables o no: "Los pasos que se dan para generar un concepto son decisiones sucesivas, las decisiones anteriores afectan los grados posibles de libertad para las decisiones posteriores" (Bruner, Goodnow y Austin, 1967: 54).

El logro en la generación de conceptos implica tomar una gran cantidad de decisiones, que presentan ciertas regularidades y que permiten generar inferencias. ${ }^{8}$ Las regularidades se convierten en estrategias, ${ }^{9}$ a las que el sujeto recurre de manera inconsciente, para adquirir, retener y utilizar la información. Las estrategias cambiarán de acuerdo con las demandas de la situación, la definición de la tarea, las expectativas para encontrar una solución satisfactoria y la naturaleza del concepto.

Entra aquí la idea de comportamiento en la búsqueda de información de un sujeto, la intromisión de estímulos externos genera una tensión y un problema para categorizarlos y conceptuarlos, lo que lo lleva a tomar decisiones que se convertirán en estrategias y que determinarán su comportamiento, en nuestro caso en la búsqueda, recuperación y uso de la información.

Asimismo, la frase expectativas para encontrar una solución satisfactoria implica textualmente una satisfacción (o no) por las decisiones tomadas, lo que nos remite de facto a la satisfacción de usuarios. Si bien ésta se ha concebido tradicionalmente como un conjunto de medidas o parámetros que el sistema

8 Se entiende por inferencia a la proposición (conclusión) derivada de premisas, ideas o proposiciones anteriormente construidas.

9 Una estrategia es un patrón de decisiones que se pueden observar en la búsqueda de la solución de un problema para generar un concepto. 
de información establece para evaluar su actuación con el usuario, en realidad debería basarse en un sujeto/usuario, en medir su estado mental y afectivo (representado en un lenguaje, comportamiento y actitud) hacia el sistema, en si se cubren o no sus expectativas, y en saber si las posibilidades de solución que les estamos ofreciendo disminuyen su tensión y frustración.

El aprendizaje de nuevas categorías y el logro de conceptos pretenden crear consecuencias anticipadas, éstas se relacionan con las decisiones y se crean tres suposiciones:

La primera [...] cada paso en una actuación puede ser finalmente recordado como una opción o decisión entre pasos alternativos. La segunda [...] es necesario considerar las consecuencias no sólo del paso dado por el tomador de decisiones sino también del que no se dio. La tercera aseveración es que las consecuencias esperadas de una decisión pueden ser analizadas desde dos componentes [...] la probabilidad estimada de la ocurrencia de los resultados alternativos y el valor dado [...] a los resultados anticipados (Bruner, Goodnow y Austin, 1967: 72-73).

Llevándolo al plano del usuario tendremos que identificar cada paso que dio, por qué lo dio, los que no dio y cómo lo justifica, y de aquí anticipar su comportamiento y apoyarlo más objetivamente, es claro que los resultados esperados dependen de los objetos particulares de los individuos. Esto nos llevaría a pensar (con un alto grado de temor) que nuestro hacer sería identificar los comportamientos en forma individual; sin embargo cada individuo se puede acomodar junto a otro que muestre características semejantes y así tendríamos comunidades y no individuos.

La tendencia cognitiva nos lleva a identificar la importancia del proceso de categorización perceptual y conceptual, pero en especial esta última pues aislar y usar un concepto está profundamente fijado en la fábrica de la vida cognitiva, esta actividad conlleva una utilidad funcional pues le permite al organismo (sujeto, usuario) adaptarse a su medio ambiente. Según Bruner, Goodnow y Austin: "El hombre no es una máquina lógica, pero es capaz de tomar decisiones y reunir información en una manera que refleja mejor su capacidad de aprendizaje" (1967: 79).

Aparecen como constantes los términos necesidad, información, concepto, conocimiento, comportamiento, solución de problemas, toma de decisiones, estrategias, expectativas, satisfacción, intención, objetivos del individuo y aprendizaje, todos ellos forman parte del fenómeno usuarios de la información. 


\section{El ENFOQUe COGNITIVO}

\section{Y EL FENÓMENO USUARIOS DE LA INFORMACIÓN}

La intención de explicar fenómenos referidos a la información y su uso desde el enfoque cognitivo no es nueva, aparece desde la década de los años setenta del siglo pasado. Quienes empezaron a seguirla fueron los estudiosos de la Ciencia de la Información (CI), esta disciplina aparece aproximadamente en los sesenta y surge como una respuesta profesional a la gran producción de información y a la introducción de las computadoras en la generación, almacenamiento y transferencia de información. Estos aspectos precisaron que el profesional de la información volteara a ver al sujeto que recupera y usa esa información y se generó así la consideración de los requerimientos de los usuarios, los cuales son nombrados necesidades de información, y como objeto de estudio declararon a la información (Belkin, 1977; Brookes, 1980; Mey, 1980).

Si bien estos antecedentes ubican el seguimiento de la tendencia cognitiva en la ciencia de la información en la década de los setenta, una búsqueda exhaustiva sobre el tema arrojó que existen sólo unos pocos autores y documentos que la abordan.

De acuerdo con Mey (1980) el establecimiento de una nueva disciplina denominada Ciencia Cognitiva se da con la publicación de las obras Explanation in cognition y Representation and understanding en los años setenta del siglo XX. Esto permitió que investigadores de diversas disciplinas adoptaran el punto de vista cognitivo como su referente teórico, situación que se da también en la CI, como un estadio evolutivo.

Este autor establece que el estudio de la información se ha desarrollado en cuatro etapas principales:

1. Una etapa monádica durante la cual las unidades de información son manejadas separada e independientemente una de otra como si fueran simples entidades autocontenidas.

2. Una etapa estructural en la que la información es vista como una entidad más compleja consistente en algunas unidades de información arregladas de una manera específica.

3. Una etapa contextual en la que además de un análisis de la organización estructural de las unidades de información puras, existe información requerida en un contexto para esclarecer la ambigüedad del significado del mensaje.

4. Una etapa cognitiva o epistémica en la cual la información es vista como suplementaria o complementaria a un sistema conceptual que representa 
el procesamiento de información del sistema de conocimiento de su mundo (Mey, 1980).

Concretamente en el campo de usuarios de la información el enfoque cognitivo se empieza a seguir a finales de los años setenta. Si bien pareciera que considerar los procesos mentales para explicar fenómenos referidos a la información conlleva directamente a aplicar sus principios al área de usuarios, lo cierto es que, antes de llegar a esta área, se explicaron otros campos de investigación como la clasificación o el diseño de sistemas de recuperación de información.

Un evento significativo en la promoción y consolidación del seguimiento del paradigma cognitivo se da hasta la década de los noventa, con la organización de la Segunda Conferencia Internacional de la Sociedad Internacional para la Organización del Conocimiento (ISKO por sus siglas en inglés: International Society for Knowledge Organisation), cuyo título fue Los paradigmas cognitivos en la Organización del Conocimiento (1992). En ese foro se presentaron trabajos relacionados con el punto de vista cognitivo aplicado a distintas áreas, por ejemplo a la clasificación. Seetharama (1992) expresa que ya desde 1958 Ranganathan introduce la idea de que se debía investigar la forma en la que la mente humana piensa, esto le permite años después (1966) crear su idea de sintaxis absoluta, que representa la "[...] secuencia en la cual los componentes de las ideas de las materias caen en las mentes de la mayoría de intelectos normales como un arreglo de campos temáticos, [...]” (Seetharama, 1992: 286).

Cabe mencionar que han existido diferentes posturas en relación con este enfoque, algunos están a favor y otros en contra. Tal es el caso de autores como Frohmann (1992a), quien critica el punto de vista cognitivo porque considera que apoya la ideología moderna del capitalismo, se mira a la información como un bien económico y a los usuarios como consumidores de información encuestables (procesables por máquina), como sujetos que consumen las imágenes y las representaciones del mundo capitalista circundante, no crean representaciones, las consumen del entorno: "El consumo es tremendamente amplio cuando las imágenes y las representaciones se convierten en necesidades, y cuando el consumo del objeto material deviene en representar el consumo de una imagen" (Frohmann, 1992b: 369).

Otro tema de crítica para Frohmann es el que se refiere a la imposibilidad de representar lo cognitivo en el diseño de sistemas de información automatizados, al final estos son diseñados siguiendo los criterios de los ingenieros, sin considerar el mundo abstracto de los sujetos. Por último resalta que no es concebible comparar el proceso mental de conocimiento con un sistema de información computarizado. 
Es importante resaltar la clasificación que Frohmann (1992a) hace de la CI, sus campos fenoménicos corresponden a las funciones que se realizan en una unidad de información (servicio de consulta; indización; servicios para niños; clasificación; comportamiento en la búsqueda y recuperación de información) y no a fenómenos disciplinarios (organización; usuarios; diseño de sistemas de búsqueda y recuperación de información), esto indica el seguimiento del paradigma profesional de la institución de información.

Se considera que las críticas de Frohmann son más de corte económico y social que de uno académico. La idea de seguir el punto de vista cognitivo es explicar una disciplina, generar teoría, es claro que los paradigmas y marcos teóricos están insertos en un devenir histórico-social que influye en ellos; sin embargo, se debe adoptar un pensamiento o tendencia teóricos para producir el conocimiento que consolida una disciplina.

Como es posible apreciar existen algunos autores que no están de acuerdo en seguir esta tendencia teórica, y otros que la han seguido en forma consistente; a continuación se presentan aquellos que la han aplicado específicamente al fenómeno usuarios.

Los precursores más relevantes en seguir el punto de vista cognitivo para explicar fenómenos referidos a la información y a los sujetos que la usan fueron M. de Mey (1977); N. J. Belkin (1977); B. C. Brookes (1980); B. Dervin (1983); T. D. Wilson (1984) y P. Ingwersen (1984). A continuación se describen sus aportaciones.

\section{Marc de Mey (1977)}

Para Mey "[...] cualquier proceso de información, ya sea perceptual o simbólico, es mediado por un sistema de categorías o conceptos, los cuales para el dispositivo de procesamiento de información, son un modelo del mundo" (1980: 48).

Las áreas cognitivas que más le interesan son la percepción y el entendimiento del lenguaje. Enfatiza la idea de contexto, el cual estará suministrado por el conocimiento que el sujeto que percibe o escucha invoca para analizar una señal y determinar su significado. "Es el conocimiento el que le permite buscar y detectar muy selectivamente aquellas características estructurales y aquellos elementos del contexto que producen una interpretación del mensaje que es congruente con el conocimiento" (Mey, 1980:54).

Con respecto a la representación del conocimiento, establece que éste no es una colección de conoceres o unidades de conocimiento, ya sean afirmaciones, exposiciones o proposiciones, "ordenadas de tal forma que permitan aplicar la deducción al todo” (Mey, 1980: 55); en realidad el conocimiento es un proceso: 
la adquisición de conocimiento y procesamiento de información se construyen en un esquema de acción, postura que será retomada por Brenda Dervin.

Introduce términos como visión del mundo o estructura, examina la forma en la que el conocimiento científico es generado y estructurado, pero se fija en procesos como entendimiento y significado: cómo los entendimientos compartidos impulsan las especialidades científicas, es decir, atiende a la clasificación disciplinaria; y cómo se atribuye un significado a ciertos datos de acuerdo con el contexto dentro del cual son producidos, la disciplina a la que se refieren y los métodos paradigmáticos adoptados.

Genéricamente alude al paradigma para establecer las imágenes del mundo y los significados que un sujeto posee, lo cual circunscribe su aportación a la producción de conocimiento formal.

\section{N. J. Belkin (1977)}

Considera que los estados de conocimiento, creencias y cualquier elemento interactúan con lo que los sujetos perciben, reciben o producen. A partir de esta afirmación critica el abordaje meramente lingüístico, el cual se ha concentrado explícitamente en la estructura del texto y se ha referido poco al comportamiento del sujeto asociado con los textos; en ese momento no existía una relación directa de significado para una representación compatible con la necesidad de información.

Belkin retomó procesos mentales como la estructura de la memoria, el recuerdo y la recuperación de categorías, y los relacionó con la estructura de los textos, de ahí que en esa época su principal enfoque cognitivo tenga que ver con "los modelos de la memoria que pueden aproximarse a los modelos de conocimiento conceptual” (Belkin, 1977: 18) y no sólo a modelos lingüísticos.

Para él las representaciones mentales de modelos de categorías y modelos de redes semánticas que poseen los sujetos y que están en un proceso constante de generación son básicas para analizar y describir el significado, el entendimiento y el efecto de los textos como un todo. Basa sus explicaciones en una red jerárquica de significados (o conceptos) a la que atiende la memoria cuando trata de acomodar ideas y comprender un texto.

Ya en la década de los ochenta crea un modelo denominado sistema cognitivo de comunicación para la recuperación de información, el cual sugiere que la base de cualquier sistema debe ser el problema del usuario, representado por un estado anómalo (irregular) de conocimiento (ASK por sus siglas en inglés: Anomalous State of Knowledge). Lo que dirige al usuario para buscar información son sus objetivos, problemas y conocimiento, y estos elementos conformarán la representación a tener en cuenta, más que la representación 
de los documentos, siempre a partir de la funcionalidad y arquitectura de los sistemas de información inteligentes basados en computadoras.

Para aplicar su modelo define necesidad de información como una brecha de conocimiento entre lo que el usuario desea saber y lo que sabe, esta definición ha sido utilizada ampliamente por otros autores.

Hacia los años noventa, resalta los procesos mentales como base para diseñar sistemas de recuperación de información y enfatiza la perspectiva del usuario en cuanto al proceso de recuperación de información, su declaración central es descubrir la naturaleza del conocimiento que impulsa a los usuarios a entrar en determinados sistemas. Por lo que: “[...] es apropiado considerar la naturaleza del estado mental del usuario al diseñar sistemas cuyo propósito sea la eventual y apropiada modificación del estado de conocimiento del usuario" (Belkin, 1990: 14).

\section{B. C. Brookes (1980)}

Introduce el enfoque cognitivo para sentar los fundamentos teóricos de la CI, y basándose en la teoría de Popper sobre el conocimiento científico describe los tres mundos que se tienen que considerar para abordar el fenómeno de la información, los sistemas de información y el problema específico de la recuperación de información: Mundo 1, el mundo físico; Mundo 2, el mundo subjetivo del conocimiento humano o estados mentales; y el Mundo 3, el mundo del conocimiento objetivo; es decir, los productos de la mente humana registrados en lenguajes, artes, ciencias y en tecnologías.

Si bien pareciera que para la Ciencia de la Información el énfasis debería haber estado en el Mundo 3, Brookes desarrolla con mayor amplitud lo relacionado con el 2, los aspectos mentales o cognitivos. Acotemos la ecuación fundamental de la relación entre la información y el conocimiento, que es considerada como la estructura del conocimiento (Brookes, 1980: 128):

$\mathrm{K}[\mathrm{S}]+\Delta \mathrm{I}=\mathrm{K}[\mathrm{S}+\Delta \mathrm{S}]$

Donde:

$\mathrm{K}[\mathrm{S}]$ = Estructura de conocimiento

$\Delta \mathrm{I}=$ Información (efecto de modificación)

$\mathrm{K}[\mathrm{S}+\Delta \mathrm{S}]=$ Nueva estructura modificada por la información

Esta ecuación implica que la información y el conocimiento están en la misma clase, y que la información es interpretada y absorbida (acomodada) 
dentro de una estructura de conocimiento, no en forma simplemente de adición, sino que se ajusta con los conceptos y relaciones conceptuales previamente adquiridos por un sujeto; asimismo, establece que esta ecuación puede ser aplicada tanto al conocimiento subjetivo como al objetivo: "[...] el crecimiento del conocimiento que es registrado en literatura publicada refleja las formas como un individuo piensa en privado" (Brookes, 1980: 131).

Por supuesto que para él la estructura cognitiva es producto de procesos mentales y declara que entre los dos elementos esenciales que integran un sistema de comunicación (también entendido como sistema de información), emisor y receptor, se realizan procesos cognitivos.

Retoma la importancia del lenguaje como la expresión última de lo cognitivo, aunque enfatiza la adquisición de información mediante mecanismos sensoriales. Esta ecuación de la estructura del conocimiento y la información es utilizada por varios autores, entre ellos Belkin, Mey e Ingwersen.

\section{B. Dervin (1983)}

Si bien esta autora no declara que sigue una tendencia cognitiva, todo su modelo, al cual denomina sense-making (en su propia denominación nos remite de inmediato a la categorización de Bruner, Goodnow y Austin) está permeado por ella.

El sense-making es una metodología que surge del estudio de la práctica de la información y considera las construcciones que los sujetos hacen en los momentos en que tienen que darle sentido (make-sense) a las experiencias relacionadas con la información: necesidades, búsqueda y uso de la información. Su base explicativa es la discontinuidad en las actividades que realiza cotidianamente un sujeto, con el fin de darles sentido.

Más puntualmente la influencia de la categorización de Bruner se hace patente en la metáfora operativa que crea, la cual se basa en su idea de discontinuidad:

Se centra en el individuo en el momento de discontinuidad, el detenimiento que no le permite, desde su percepción, moverse hacia adelante sin construir un nuevo sentido. Determina la forma como el individuo interpreta y construye puentes en ese momento: qué estrategia usó para definir la situación en la que la brecha estaba; cómo conceptualiza la discontinuidad como brecha y el puente que la cruza; cómo se movió tácticamente para crear el puente; cómo procedió durante el trayecto después de cruzar el puente (Dervin, 2003: 277).

De acuerdo con esta metáfora la generación de sentidos en las actividades de un sujeto depende de cómo acomode los momentos de discontinuidad y 
cómo haga para lograr la continuidad. Esta mirada somera a su modelo nos muestra la influencia del enfoque cognitivo.

\section{T. D. Wilson (1984)}

Retoma los conceptos expuestos por Mey, imagen y visión del mundo, y marco o estructura de referencia, y afirma que la forma en que un sujeto percibe la realidad afecta su comportamiento, el cual variará de acuerdo a cómo los conceptos mencionados estén constituidos, formados y cambiados.

Por esa época Wilson estaba enfrascado en el estudio del comportamiento en la búsqueda de información (el que posteriormente derivará en comportamiento informativo) de los usuarios; así, para él:

El propósito de una aproximación cognitiva al comportamiento en la búsqueda de información y su uso, [...] es descubrir cómo las imágenes y marcos de referencia de la gente [...] se relacionan con la disponibilidad de la información, cómo la elección de la información es determinada por la imagen, y cómo la información puede cambiar la imagen, o afecta un marco de referencia (Wilson, 2008).

La esencia del enfoque cognitivo es la idea de la percepción humana, la cognición y las estructuras de conocimiento.

\section{P. Ingwersen (1984)}

Parte del proceso de recuperación de información y lo relaciona con diversos procesos mentales: solución de problemas, aprendizaje, percepción, conceptualización, pensamiento, representación, categorización del conocimiento, comportamiento comunicativo, memoria y algo que llama procesamiento psicológico de la información (que en sentido estricto de acuerdo con los principios de la psicología cognitiva sería el total de todos los anteriores). Considera que para explicar el proceso de recuperación de información se deben retomar varias disciplinas cognitivas: lingüística y filosofía de la mente; y otras no cognitivas: matemáticas, biología, ingeniería, sociología y ciencia de la computación.

Al igual que Belkin declara que la CI se ha basado en la organización de los documentos para acomodarlos juntos y no en los factores psicológicos y lingüísticos que subyacen en la generación profunda del conocimiento; afirma que en ambas posturas la creación y la clasificación del conocimiento implican conceptuar, categorizar y pensar (Ingwersen, 1982).

Diferencia entre representaciones documentales y representación del conocimiento, la primera es la que más se ha seguido. Asimismo, abunda en que 
las teorías lingüísticas de Chomsky han inspirado el desarrollo de la clasificación facetada, los sistemas estructurales de indización como KWIC (Key Word in Context), KWOC (Key Word out Context), SAP y esquemas como PRECIS.

$\mathrm{Su}$ modelo denominado The library communication system from a cognitive point of view, que data de 1982, expresa la necesidad de considerar las estructuras cognitivas de cualquier sujeto (usuario, intermediario o bibliotecario) que intervenga en un modelo complejo de sistema de comunicación en una biblioteca:

Los elementos más importantes relacionados con las negociaciones usuario-intermediario y la interfase investigador-sistema están vinculados con la percepción, memoria, recuerdo y reconocimiento de conceptos, procesamiento de información, aprendizaje y constante solución de problemas y toma de decisiones ya sea para el intermediario y para el que busca. Más aún, la entrevista involucra comunicación y comportamiento interpersonal (Ingwersen, 1984: 86).

Para él lo importante ha sido estudiar la negociación entre el usuario y el bibliotecario, la interpretación del bibliotecario del requerimiento del usuario; afirma que los problemas centrales concernientes al procesamiento de la información en un sistema de recuperación son básicamente de naturaleza psicológica y lingüística, lo que reitera los principios del enfoque cognitivo.

Como es posible apreciar estos estudiosos siguen los principios de categorización de Bruner, Goodnow y Austin anteriormente explicados, y ubican al usuario como un ente con estados mentales quien representa los estímulos/ información de acuerdo con su acervo cognitivo y sus marcos de referencia ambientales o contextuales.

Es interesante percibir el compromiso de todos estos autores por seguir puntualmente el enfoque cognitivo y lograr consistencia en sus hallazgos, los estudiosos de los usuarios de la información debemos generar marcos teóricos a partir de entender al sujeto como un ente que piensa y actúa de acuerdo con este pensar, entenderlo y posteriormente describirlo desde su acervo de conocimientos nos permitirá avanzar como una comunidad epistémica consolidada.

\section{Conclusiones}

Las ciencias cognitivas aparecen en la década de los cincuenta del siglo pasado y desde entonces hasta ahora han permitido describir fenómenos pertenecientes a diversas disciplinas, en nuestro caso el campo fenoménico denominado 
usuarios de la información, ubicado dentro de la bibliotecología y las ciencias de la información. Las ciencias cognitivas se rigen por tres principios: la computación, las representaciones y la perspectiva interdisciplinaria; y son la base del enfoque cognitivo. Se ubican como disciplinas cognitivas la filosofía de la mente, la inteligencia artificial, la neurociencia, la lingüística, la antropología psicosocial y la psicología cognitiva.

Resalta para nuestro estudio esta última ya que se encarga de entender a la mente humana, los procesos mentales y la representación y uso del conocimiento, todo esto se relaciona directamente con el sujeto que usa la información, es decir, nuestros usuarios.

Entre los procesos de cognición está la categorización, este proceso le permite a cualquier sujeto conceptualizar, convertir ideas diferentes en equivalentes y agrupar objetos, hechos y personas de acuerdo con una clasificación o ubicación de pertenencia, lo que posibilita generar necesidades y comportamientos; lo que nos interesa principalmente son las necesidades, los comportamientos y los usos de la información.

Este enfoque se empezó a seguir en la ciencia de la información hacia finales de 1970 para delimitar el concepto de información, explicar los principios de la clasificación y diseñar sistemas de recuperación de información hasta llegar a definir las necesidades de información de los sujetos y sus comportamientos ante ella.

Los primeros en utilizar la tendencia teórica cognitiva fueron Mey, Belkin, Brookes, Dervin, Wilson e Ingwersen, quienes abordaron fenómenos referidos a la información en general, al diseño de sistemas de información, al comportamiento en la búsqueda de información y al uso de la información.

Explicar fenómenos de investigación con fines de construcción de marcos teóricos exige tomar una postura para observarlos, analizarlos y sintetizarlos, en el caso de los usuarios de la información el punto de vista cognitivo es el más acertado pues les dará coherencia a los procesos mentales y de comportamiento que ese sujeto/usuario realiza ante y con la información.

\section{OBRAS CONSULTADAS}

Belkin, N. J. (1990), “The cognitive viewpoint in information science", en Journal of Information Science, 16, pp. 11-15. (1977), Lingüistic and cognitive models of information and state of knowledge, United Kingdom: British Library Research \& Development Department.

Brookes, B. C. (1980), "The foundations of information science. Part I: philosophical aspects: classes of things and the challenge of human individuality", en Journal of Information Science, 2, pp. 125-133. 
Bruner, J. S.; Goodnow, J. J.; Austin, G. A. (1967), A study of thinking, New York: Science Editions, Inc.

Dervin, B. (c2003), Sense-making methodology reader: selected writings of Brenda Dervin, Cresskill, New Jersey: Hampton Press.

Ellis, D. (1992), "The physical and cognitive paradigms in information retrieval research", en Journal of Documentation, March, 48 (1), pp. 45-64.

Ferrater Mora, J. (2001), Diccionario de Filosofía, Barcelona: Editorial Ariel, 4 vol.

Friedenberg, J.; Silverman, G. (2006), Cognitive science: an introduction to the study of mind, Thousand Oaks, California: Sage.

Frohmann, B. (1992a), "Cognitive paradigms and user needs", en Cognitive paradigms in knowledge organization. Second Internationl ISKO Conference (2:1992:Madras, India), Madras: Sarada Ranganathan Endowment for Library Science, pp. 35-50.

_ (1992b), "The power of images: a discourse analysis of the cognitive viewpoint”, en Journal of Documentation, December, 48 (4), pp. 365-386.

Hernández Salazar, P. (2007), "De la organización al uso: un cambio de paradigma bibliotecológico", en Tópicos de investigación en Bibliotecología y sobre la información: edición conmemorativa de los XXV años del Centro Universitario de Investigaciones Bibliotecológicas, Filiberto Felipe Martínez Arellano y Juan José Calva González (comps.), México: UNAM, Centro Universitario de Investigaciones Bibliotecológicas, pp. 157-186.

Ingwersen, P. (1982), "Search procedures in the library-analysed from the cognitive point of view", en Journal of Documentation, 38, pp. 165-191.

(1984), "Psychological aspects of information retrieval", en Social Science Information Studies, 4, pp. 83-95.

(1992), Information Retrieval Interaction, London: Taylor Graham.

Kunh, T. S. (2001), La estructura de las revoluciones científicas, México: Fondo de Cultura Económica.

Martorell, J. L.; Prieto, J. L. (2002), Fundamentos de la psicología, Madrid: Centro de Estudios Ramón Aceres.

Mey, M. de (1977), "The cognitive viewpoint: its development and its scope", en M. de Mey (ed.), International Workshop on the Cognitive Viewpoint, Ghent: University of Ghent.

(1980), "The relevance of the cognitive paradigm for information science", en Theory and application of information research, London: Mansell, pp. 48-60.

Neisser, U. (1967), Cognitive psychology, New York: Appleton Century-Crofts.

Seetharama, S. (1992), "Cognitive approach in information consolidation”, en Cognitive paradigms in knowledge organization. Second Internationl ISKO Conference (2:1992:Madras, India), Madras: Sarada Ranganathan Endowment for Library Science, pp. 286-292. 
Wilson, T. D. (2008), The cognitive approach to information-seeking bebavior and information use, disponible en http://information. net/tolw /publ/papers/cogapp84.html (Fecha de consulta: 11 de octubre de 2008).

$\infty$ 